\title{
Polymer films as sensitive coatings for quartz crystal microbalance sensors array
}

\author{
I.A. Koshets, Z.I. Kazantseva, Yu.M. Shirshov \\ V. Lashkaryov Institute of Semiconductor Physics, NAS of Ukraine, 41, prospect Nauky, 03028 Kyiv, Ukraine \\ E-mail:koshets@isp.kiev.ua
}

\begin{abstract}
This work reports on the results of investigation of quarts crystal microbalance sensors coated with polybutyl methacrylate and polyvinyl formal/ethylal to wide range of volatile organic compounds. Polymer film coated sensors showed a high sensitivity and an excellent selectivity towards these compounds. Good linearity of the concentration dependence has been obtained in almost all the concentration range of volatile compounds. The detection limit of several analytes was less than $100 \mathrm{ppm}$.
\end{abstract}

Keywords: quartz crystal microbalance sensor, polymer coating, volatile organic compounds.

Paper received 06.11.03; accepted for publication 11.12.03.

\section{Introduction}

Nowadays a great attention is paid to creation and development of miniaturized, low-cost, smart chemical sensing systems based on various physical and chemical principles, which provide accurate and reliable real-time control of ambient medium [1-2]. One of the most important problems under creation of such systems (known as "Electronic noses") for pattern recognition of smells is the choice of appropriate sensitive materials used as coatings of such a sensor. Requirements that should be met with these layers are quite versatile and even contradictious. On the one hand, the sensor should provide good and quick response to the presence of analyzed molecules in ambient air, on the other hand, the sensor must have sensitivity to the interfering molecules as less as possible. Besides, the sensor should be easily cleaned. From this viewpoint, various types of polymers are very promising materials, and many researchers focus their attention on investigations of selective and sensitive properties of polymer films [3-5]. This work is aimed at the study of polybutyl methacrylate (PBMA) and polyvinyl formal ethylal (PVFE) as sensitive layers for (quarts crystal microbalance) QCM sensor.

\section{Experimental}

The basis of QCM technique is the proportionality between mass loaded onto quartz surface and oscillations frequency shifts in according to the Sauerbrey equation [6]. So, measuring the frequency shift, one can easily investigate adsorption-desorption processes occurring at onto sensor surface. Sensitivity of this method is very high $1-2 \mathrm{ng} / \mathrm{Hz}$, which allows detecting the very low concentration of organic vapors. 8-channel QCM sensor system with all the necessary equipment (gas cell, gas-supplying system and electronic circuits, etc.) designed in our laboratory has been used in experiments. The experiment control and data acquisition were implemented with $\mathrm{PC}$ by means of domestic software. Gas-supplying regime chosen for our experiments was of non-flow type: after rapidly injected analyte gas, the cell was cut off from pipeline and no gas flow occured during the measuring period. The detailed description of this device and gas supplying regime can be found in [7].

Polymers were deposited onto quarts surface by means of dipping and spin coating techniques. Information about morphology and determination of the thickness of layers deposited has been was obtained from ellipsometry and AFM measurements. The average film thickness was about 50-70 $\mathrm{nm}$ (on each side of quartz sensor), which corresponds to $2000-3000 \mathrm{~Hz}$ frequency shift. After deposition, sensors were dried with fresh dry air for 12-15 hours to draw out the remaining solvent from coatings. Chemical structures of polymers are shown in Fig. 1.

Such volatile organic compounds as chlorbenzene $\left(\mathrm{C}_{6} \mathrm{H}_{5} \mathrm{Cl}\right)$, benzene $\left(\mathrm{C}_{6} \mathrm{H}_{6}\right)$, toluene $\left(\mathrm{C}_{7} \mathrm{H}_{8}\right)$, dichloromethane $\left(\mathrm{CH}_{2} \mathrm{Cl}_{2}\right)$, carbon tetrachloride $\left(\mathrm{CCl}_{4}\right)$, chloroform $\left(\mathrm{CHCl}_{3}\right)$ and ethanol $\left(\mathrm{C}_{2} \mathrm{H}_{6} \mathrm{O}\right)$ were involved in our 


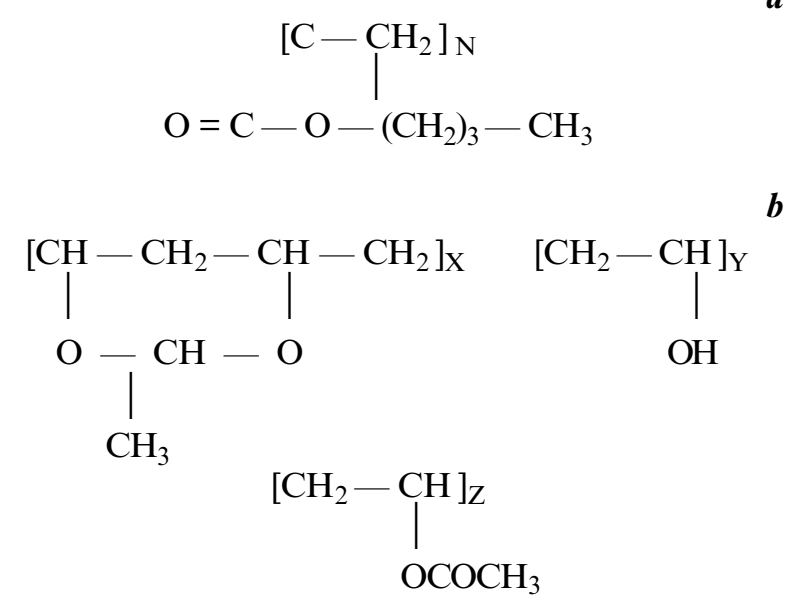

Fig. 1. Chemical structure of polymers: $a$ ) - PBMA; $b$ ) - PVFE.

experiments. The required concentration was provided with the home made vapor generating system based on the diffusion tube principle [8].

\section{Results and discussion}

Typical kinetics of sensors response to injection of different organic vapors (ethanol, dichloromethane and chlorobenzene) is presented in Fig. 2. Numbers in plots denote the concentration of analyte. Two types of the curve shape are observed: the first one - gradual ("slow") changing of the frequency shift followed by the flat part of the curve; the second - "fast" response with pronounced maximum followed by a dip of the curve. Such distinct behavior strongly depends on correlation of such factors as gas cell capacity, initial number of volatile molecules injected, numbers of sensors and cell sites, and their time constants ("slow" or "fast" they are). The detailed description of this phenomenon can be found in [2].

It was found that PMBA film coated sensor exhibited a high sensitivity and an excellent selectivity for chlorbenzene, although the sensor also responded to chloroform, chlormethelene and toluene, responses towards alcohol were insignificant. The responses of PVFE film coated show a high sensitivity towards alcohol but low sensitivity towards chlorine organic vapors. In some cases, e.g. chlormethelene, magnitude of response is similar for two polymers, but the shape of kinetic curve strongly different. It provides us extra information for goals of pattern recognition.

As known, selective features of organic sensitive layer mainly coincide with solubility parameter towards organic solvents [1]. In other words, the closer solubility parameters of given organic layer and given solvent, the higher response of the sensor coated with this layer to the vapor of that solvent. For example, solubility parameters of PBMA are closer to those of benzene and chlorbenzene but smaller than that of ethanol. Similar situation is observed in QCM measurements - sensor coated with PBMA
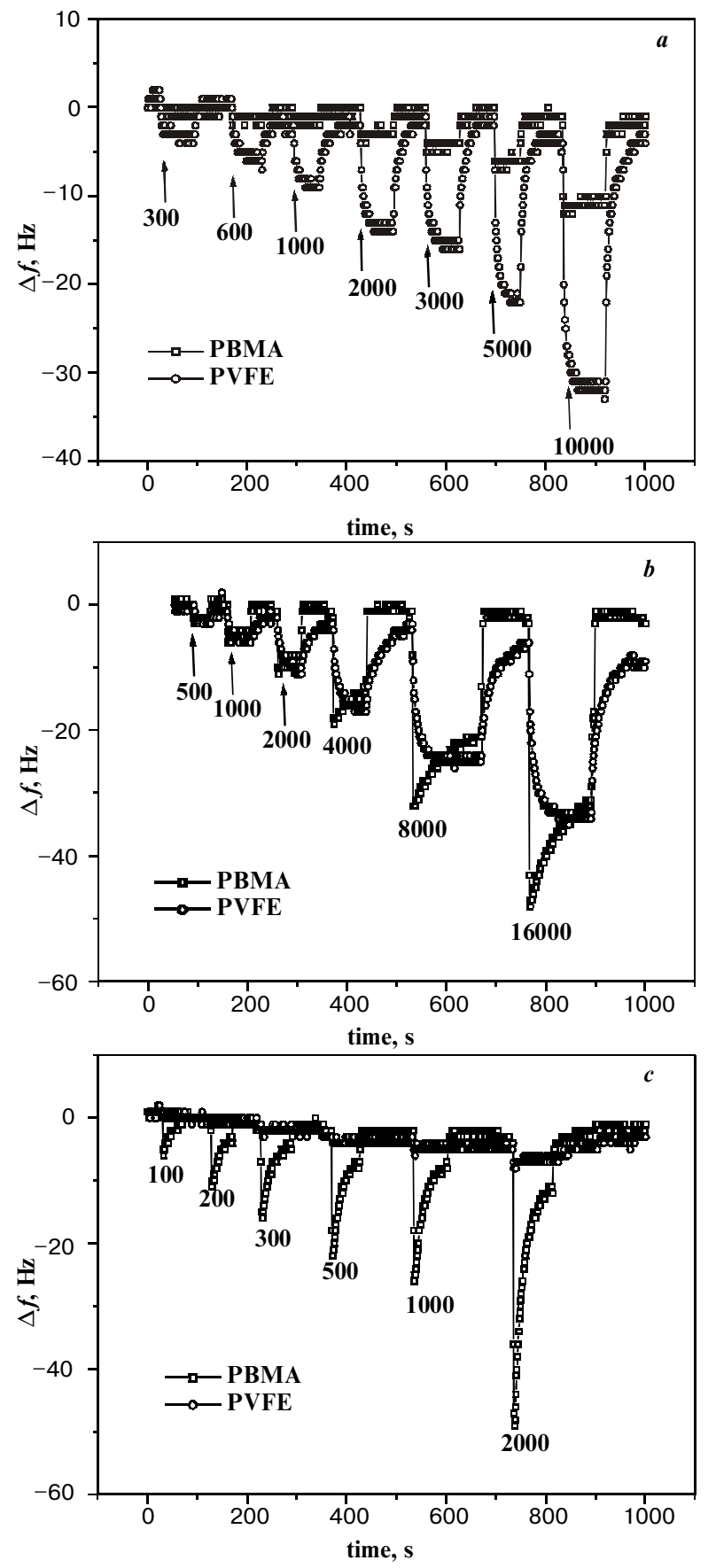

Fig. 2. Kinetic response (frequency shift) of sensors coated with polymers to injection of ethanol $(a)$, dichloromethane $(b)$ and chlorbenzene $(c)$ vapor.

shows maximal response to carbon tetrachloride vapor. Although, situation is more complicated for copolymers (PFE) consisting of different polarity monomers. In this case, the dipole-dipole interaction plays a significant role, which should be taken into account for analysis of sensing features inherent to these coatings.

Concentration dependencies extracted from kinetic curves are shown in Fig. 3. Good linearity is seen almost over all the concentration range of analytes. 


\section{I.A. Koshets et al.: Polymer films as sensitive coatings for quartz crystal ...}
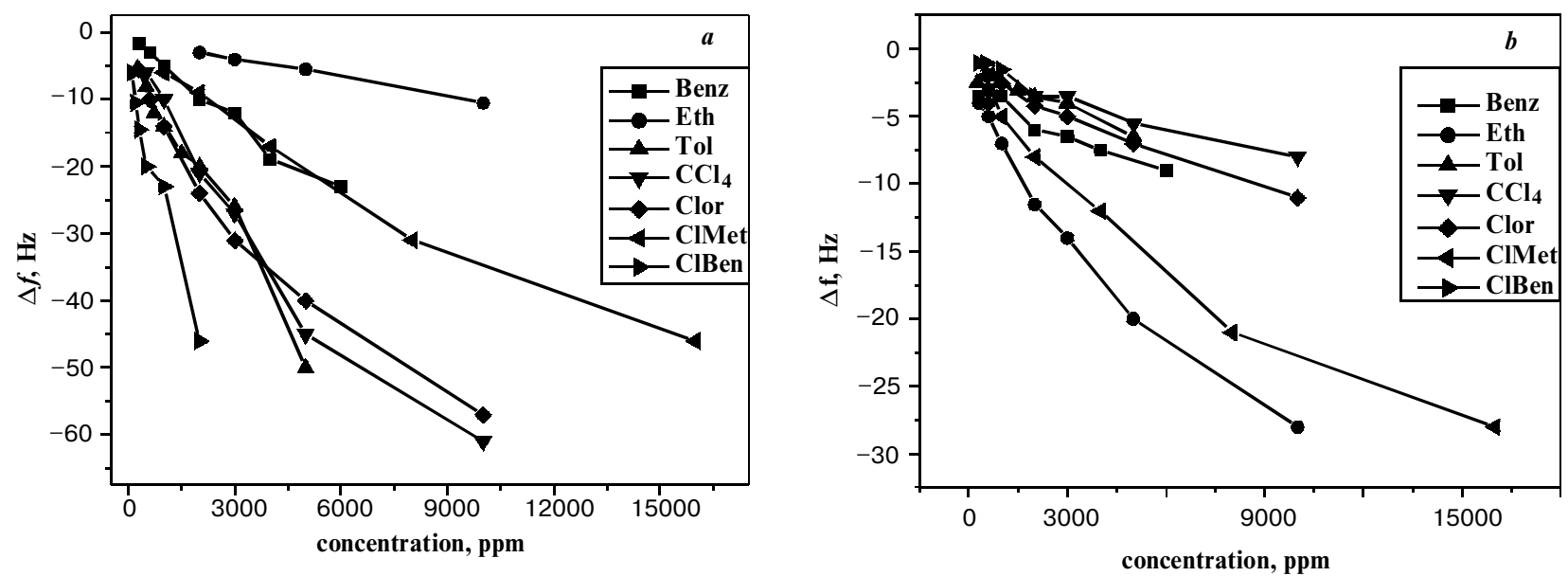

Fig. 3. Sensitivity of sensors coated with PBMA $(a)$ and PVFE $(b)$ towards various volatile organic molecules.

Table.1. Sensitivity and detection threshold of sensors coated with PBMA and PVFE.

\begin{tabular}{|l|c|c|c|c|}
\hline \hline \multirow{2}{*}{$\begin{array}{l}\text { Volatile organic } \\
\text { molecules }\end{array}$} & \multicolumn{2}{|c|}{ PBMA } & \multicolumn{2}{c|}{ PVFE } \\
\cline { 2 - 5 } & $\begin{array}{c}\text { Sensitivity, } \\
10^{-4} \times \mathrm{Hz} / \mathrm{ppm}\end{array}$ & $\begin{array}{c}\text { Detection } \\
\text { threshold, } \mathrm{ppm}\end{array}$ & $\begin{array}{c}\text { Sensitivity, } \\
10^{-4} \times \mathrm{Hz} / \mathrm{ppm}\end{array}$ & $\begin{array}{c}\text { Detection } \\
\text { threshold, ppm }\end{array}$ \\
\hline Benzene & 38.8 & 300 & 10.8 & $<300$ \\
\hline Ethanol & 9.34 & 2000 & 34 & $<300$ \\
\hline Toluene & 87.7 & $<250$ & 10.5 & $<500$ \\
\hline Carbon tetrachloride & 86 & $<500$ & 5.92 & 2000 \\
\hline Chloroform & 93.4 & $<300$ & 8.5 & 500 \\
\hline Dichloromethane & 36 & 500 & 24 & 500 \\
\hline Chlorobenzene & 34.5 & $<100$ & 17.1 & 2000 \\
\hline \hline
\end{tabular}

Slightly sublinear shape of curves in the high concentration level (one or two last points) might be related to saturation of sensitive sites in the film. Numerical values of the sensitivity and detection limit are presented in Table1.

Sensors coated with PBMA and PVFE accompanied with sensors coated with other polymers were combined into array that was successfully tested for discrimination of wide number of aromatic and chlororganic volatile compounds and several items of brandy produced in Ukraine.

\section{Conclusions}

Summarizing all mentioned above, we may conclude that polymer and copolymer are promising materials for using them as a sensitive layer of sensors elements in a chemical sensing system. Varying functional groups of polymer, we can find appropriate set of sensors for reliable recognition of volatile organic compounds in ambient atmosphere and testing the quality of alcohol beverages, perfumes, etc. Application of statistical apparatus (PCA, Neural Network, etc.) to data obtained from the sensor array allows increasing such recognition.

\section{References}

1. Ch. Ziegler, W. Gopel, at all, Bioelectronic noses: a status report. Part I // Biosensors \& Bioelectronics, 13 (3-4), pp.479493 (1998).

2. Ch. Ziegler, W. Gopel, at all, Bioelectronic noses: a status report. Part II // Biosensors \& Bioelectronics, 13, pp. 539-571 (1998).

3. S.Roster, R.Lucklum, R.Borngraber, J.Hartmann, P.Hauptmann, Sensor system for the detecion of organic pollutants in water by thickness shear mode resonators // Sensors \& Actuators. B 48, pp. 412-424 (1998).

4. R.Polikar, R.Shinar, L.Udpa, M.D.Porter, Artificial intelligent methods of an optimized sensor array for identification of volatile organic compounds // Sensor \& Actuators, B 80, pp.243-254 (2001).

5. H. Nanto, Y. Yokoi, T. Mukai, J. Fujioka, E. Kusano, A. Kinbara, Y. Douguchi, Novel gas sensor using polymerfilm-coated quartz resonator for environment monitorinq // Material Science and Engineering, C-21, pp. 43-48 (2000).

6. F.Eichelbaum, R. Borngraber, J. Schroder, R. Lucklum and P. Hauptmann, Interface circuits for QCM sensors // Review of Scientific Instruments, 70, May, 1999.

7. V.I.Kalchenko, I.A.Koshets, E.P.Matsas, O.N.Kopylov, A.Solovyov, Z.I. Kazantseva, Yu.M.Shirshov, Calixarene based QCM sensors array and its response to volatile organic vapors// Materials Science, 20 (3), pp.73-88 (2002).

8. J.M. McKelvey and H.E. Hoelscher, Apparatus for preparation of very dilute gas mixtures // Analytical chemistry, 29 (1), pp.123-124 (1957). 